\title{
Lung cancer in a non-ferrous smelter: the role of cadmium
}

\author{
A E ADES, ${ }^{*}$ G KAZANTZIS \\ From the London School of Hygiene and Tropical Medicine, London WCIE 7HT, UK
}

ABSTRACT Lung cancer mortality was examined in a cohort of 4393 men employed at a zinc-leadcadmium smelter. There was an excess of lung cancer (overall SMR $=124 \cdot 5,95 \%$ confidence interval 107-144) which was particularly evident for those employed for more than 20 years. A statistically significant trend in SMRs with increasing duration of employment was apparent. Quantitative estimates of exposure to cadmium and ordinal rankings for lead, arsenic, zinc, sulphur dioxide, and dust were used to calculate cumulative exposures from job histories. Matched logistic regression was used to compare the cumulative exposures of cases of lung cancer to those of controls matched for date of birth and date of starting work and surviving at the time of death of the matched cases. The increasing risk of lung cancer associated with increasing duration of employment could not be accounted for by cadmium and did not appear to be restricted to any particular process or department. Although lung cancer mortality was associated with estimates of cumulative exposure to arsenic and to lead, it was not possible to determine whether the increased risk might be due to arsenic, lead, or to other contaminants in the smelter. These results are compared with findings from other non-ferrous smelters.

In a study on the mortality of workers exposed to cadmium a cohort of almost 7000 men born before 1940 and exposed to cadmium for at least one year before 1970 was followed up until the end of 1979 by Armstrong and Kazantzis.' By contrast with the findings in some other studies, ${ }^{23}$ the cohort showed no excess mortality from prostatic cancer.$^{14}$ Nevertheless, a small but significant excess mortality from lung cancer was observed in men employed for more than ten years (standardised mortality ratio (SMR) 126, $95 \%$ confidence interval $(\mathrm{CI}) 102-153)$. The absence of any relation to intensity of exposure, in contrast to the large excess mortality from chronic bronchitis where a significant dose response relation was observed, led to the conclusion that the excess lung cancer mortality was unlikely to be related to past exposure to cadmium.

Subsequently, a high incidence of lung cancer in rats dosed with a cadmium chloride aerosol was reported by Takenaka et al ${ }^{5}$ and Thun et $\mathrm{al}^{6}$ found a significant excess mortality from lung cancer in smelter workers

*Present address: Department of Paediatric Epidemiology, Institute of Child Health, 30 Guilford Street, London WC1N 1EH.

Accepted 3 August 1987 exposed to cadmium, with evidence of a dose response relationship. ${ }^{6}$ It was therefore decided to make a further study of lung cancer (ICD 8th revision 162.0 162.9) in the cohort described by Armstrong and Kazantzis.' Attention was restricted to a large nonferrous smelter (identified as cohort $\mathrm{Cl} .1$ in the study by Armstrong and Kazantzis ${ }^{4}$ ) which comprised $64 \%$ of the entire cohort for which job/exposure data for cadmium were already available from this previous study, requiring only the collection of information to control for exposure to other contaminants. SMRs were calculated to assess mortality in the smelter as a whole. To examine the contribution of specific departments, processes, and contaminants in the smelter a matched case-control analysis was performed.

\section{Study material}

PROCESSES AT THE SMELTER

The site consists of several physically separate buildings housing different processes.

The earliest smelting process, horizontal distillation, which would have involved exposure to polycyclic hydrocarbons, was phased out in 1955. A second process, the vertical retort, was operated between 1936 and 1971. Here, zinc and cadmium were distilled from briquets of sinter and collected by condensation. 
In the imperial smelting process (ISP), introduced in 1950 and in full production from 1968, zinc and lead sulphide ore concentrates are roasted to form an oxidised sinter. The oxidised sinter is crushed and screened to a size suitable for charging a blast furnace together with preheated coke. Zinc vapour passes from the top of the furnace and is absorbed into molten lead in lead splash condensers, cooled, and separated as molten zinc. Molten lead and slag are tapped from the bottom of the furnace. The crude zinc and cadmium are refined in a series of refluxing operations. In a separate building cadmium metal is precipitated from solutions arising from the cleaning of sinter fumes and then purified by melting under sodium hydroxide in small furnaces in the same building.

Exposure to lead increased noticeably between 1950 and 1968, while the ISP was being developed, particularly in the furnace and sinter departments. Arsenic has always been present as an impurity in the ores, varying from $0.01 \%$ to $1 \%$ and averaging about $0.4 \%$. Copper and, from time to time, arsenic have been refined. Exposure to sulphur dioxide has inevitably been higher in the acid and sinter plants than elsewhere on the site. Between 1961 and 1971 a beryllium-copper alloy plant was also operated.

The smelter forms part of a large industrial complex that includes docks and plants for manufacturing chemicals, fertilisers, and, at one time, mustard gas.

\section{EXPOSURE ASSESSMENTS}

The data on individuals in the study include information on the jobs they have held at the plant and the duration of each one to the nearest year (including duration of periods of absence from the plant) up to 31 December 1979. There are about 60 separate job codes and the exposure assessments for cadmium assign a value to each job for each year between 1924 and 1979. In addition, exposure estimates were obtained for the same period for arsenic, lead, zinc, sulphur dioxide, and total dust. Generally, the job codes can be reduced to ten major categories. These, together with the exposure levels, are shown in table 1.

The "background" category includes all those jobs where exposures would not be considered to be above the plant's background levels. These include canteen, security, research laboratory, and cleaner jobs. The "other above background" category includes small departments or processes of short duration with appreciable exposures.

Airborne cadmium exposures in $\mu \mathrm{g} / \mathrm{m}^{3}$ were assessed by Armstrong in 1981 from environmental monitoring returns and consultation with the plant hygienist and other staff. These assessments ranged from a mean of $200 \mu \mathrm{g} / \mathrm{m}^{3}$ and $80 \mu \mathrm{g} / \mathrm{m}^{3}$ in the sintering and cadmium plants, respectively, before 1970 to 15 $\mu \mathrm{g} / \mathrm{m}^{3}$ in both departments by 1977 , and to $1 \mu \mathrm{g} / \mathrm{m}^{3}$ as an overall plant background. All these assessments are approximate but most may be considered accurate within a factor of 2 to 5 either way.

From a later biological monitoring exercise, ${ }^{7}$ urinary cadmium concentrations, indicative of long term exposure ranged from a geometric mean of $6.3 \mathrm{nmol} /$ mmol creatinine in the cadmium plant to 2.5 in the sinter. Regression of cadmium in urine against years employed in various departments suggested that one year's exposure in the cadmium plant was equivalent to about three years in the sinter. The above figures were therefore adjusted and $60 \mu \mathrm{g} / \mathrm{m}^{3}$ was taken as an average estimate of exposure in both departments (table 1).

For zinc, sulphur dioxide, lead, and dust, values on an arbitrary four point scale were assigned to each job for each year: 0 (background), 1 (low), 2 (medium), and 3 (high). Arsenic was graded as 0 (background), 1 (low), and 2 (high). These assessments were made in 1984 by the plant hygienist and another experienced staff member without knowledge of the vital status or cause of death of cohort members.

An individual's actual exposures are likely to be closer to the average levels across the site than is suggested by the exposure assessments used through-

Table 1 Major occupational categories and their levels of exposure 1927-79

\begin{tabular}{|c|c|c|c|c|c|c|c|}
\hline \multirow[b]{2}{*}{ Department } & \multirow{2}{*}{$\begin{array}{l}\text { Cohort members } \\
\text { ever exposed } \\
\text { (\% of } 4393)\end{array}$} & \multicolumn{6}{|c|}{ Exposure levels } \\
\hline & & $\begin{array}{l}\text { Cadmium } \\
\left(\mu g / m^{3}\right)\end{array}$ & Zinc & $\mathrm{SO}_{2}$ & $\begin{array}{c}\text { Arsenic } \\
\text { (Rating scales } 0,1,2,3)\end{array}$ & Lead & Dust \\
\hline $\begin{array}{l}\text { Cadmium plant } \\
\text { Sinter } \\
\text { Horizontal distillation } \\
\text { Acid } \\
\text { Furnace } \\
\text { Maintenance staff } \\
\text { Vertical retort } \\
\text { Other above background } \\
\text { Background } \\
\text { Unclassified }\end{array}$ & $\begin{array}{r}2 \cdot 8 \\
7 \cdot 8 \\
10 \cdot 8 \\
4 \cdot 2 \\
9 \cdot 7 \\
35 \cdot 0 \\
12 \cdot 0 \\
13 \cdot 4 \\
25 \cdot 4 \\
5 \cdot 0\end{array}$ & $\begin{array}{l}30-60 \\
10-60 \\
2 \\
2 \\
1 \\
5 \\
5 \\
2-20 \\
1 \\
1\end{array}$ & $\begin{array}{l}0-1 \\
1 \\
3 \\
0 \\
1 \\
1 \\
2 \\
0-3 \\
0 \\
0\end{array}$ & $\begin{array}{l}1 \\
3 \\
0 \\
3 \\
0 \\
1 \\
0 \\
0-2 \\
0 \\
0\end{array}$ & $\begin{array}{l}0-1 \\
1 \\
1 \\
1 \\
1 \\
1 \\
1 \\
0-2 \\
0 \\
0\end{array}$ & $\begin{array}{l}0-1 \\
1-3 \\
1 \\
1 \\
3 \\
2 \\
1 \\
0-3 \\
0 \\
0\end{array}$ & $\begin{array}{l}0 \\
0 \\
0 \\
0 \\
1 \\
2 \\
0 \\
0-3 \\
0-1 \\
0\end{array}$ \\
\hline
\end{tabular}


out this paper. This is, firstly, because dust originating in any process will tend to spread over the plant during transport or after escapes during maintenance or cleaning. ${ }^{8}$ Secondly, in any one week a worker would not necessarily stay within the single location designated by his job code but might work in other departments as well. ${ }^{8}$ These factors will tend to reduce the power of the study to associate different levels of assessed exposure, or different departments, with different levels of risk.

Average arsenic levels assessed by static samplers between 1981 and 1983 ranged from $1-3 \mu \mathrm{g} / \mathrm{m}^{3}$ in the sinter and 4-7 $\mu \mathrm{g} / \mathrm{m}^{3}$ in the furnace. The biological monitoring results show average lead in blood concentrations from a low of $28 \mu \mathrm{g} / 100 \mathrm{ml}$ in the cadmium plant to 59 in the furnace and 56 in the sinter.'

\section{STUDY POPULATION}

Included in the study were all hourly paid male workers employed at the smelter on 1 January 1943 and those who subsequently started work before 1970 . Only those who were born before 1940 and who had worked for at least one year were included.

Of the $\mathbf{4 3 9 3}$ men in the cohort at the follow up date of 31 December 1982, $32(0 \cdot 7 \%)$ could not be traced, $142(3.2 \%)$ had emigrated, and $1659(37.8 \%)$ had died, 182 of lung cancer. A total of 4173 men, of whom 174 died of lung cancer, were followed up for over 10 years.

\section{Methods}

STANDARDISED MORTALITY RATIOS

SMRs were calculated using the Oxford person-years program, adjusted to permit regional correction. Person-years at risk were calculated from 1 January 1943 or from one year after starting work, whichever was the later. Exit from the study was at the date of emigration or death, the 85th birthday, or 31 December 1982, whichever was the earlier. The date of exit of untraced individuals was considered to be their date of leaving employment if this was known; otherwise they contributed no years at risk.

Following Armstrong and Kazantzis,' SMRs were regionally adjusted using the 1969-75 lung cancer SMR of 87 for South West Urban Aggregates. This compares with an SMR of 103 for Bristol County Borough and $\mathbf{7 4}$ for South West Rural Aggregates. No allowance was made for periods of absence during employment at the smelter when aggregating years at risk by duration of employment. Confidence intervals and significance tests were based on the Poisson distribution. The relation between SMR and duration of employment was analysed by the method of Berry, using the GLIM statistical package. ${ }^{10}$
MATCHED LOGISTIC REGRESSION (MLR)

A matched case-control study may be constructed from longitudinal data by selecting a set of controls for each case of lung cancer, matched for date of birth and date of starting work and surviving the case. The theoretical basis for this method is described elsewhere. "12 Matched logistic regression, unlike SMR analyses, allows the association between mortality and several environmental contaminants to be examined simultaneously and risk to be assessed relative to internal controls. For each of the 174 cases with at least 10 years follow up, controls were selected who satisfied the following criteria:

(a) born within one year of the case;

(b) started work within three years of the case;

(c) had been followed up for at least 10 years, and had necessarily worked for at least one year at the time of the death of the case; and

(d) exit from the study (defined as for SMRs) was later than the death of the case.

For efficient computing, and with negligible loss of statistical power ${ }^{12} 20$ controls were selected at random for 95 cases for whom over 20 controls were available. There were, eventually, 174 matched sets including 2717 controls. The logistic regressions were computed by the PECAN program. ${ }^{13}$ Hierarchically nested models were evaluated by comparison of the chisquared likelihood ratio statistics. Confidence intervals for estimated log relative risks of individual factors were derived from their estimated standard errors.

Subjects followed up for under 10 years were excluded..$^{14}$ This reflects the common assumption of a minimum 10 year latent period in the "initiation" of lung cancer. Cumulative exposures were calculated by summing the year by year exposure assessments over the period of employment up to three years before the death of the case to whom controls were matched. This effectively assumes that "promoting" effects have a three year latency. Three years is about the time taken for lung cancer rates to fall in people who have given up smoking cigarettes relative to those who continue. ${ }^{15}$ Our experience, however, is that the results are fairly insensitive to changes in the assumptions about initiation and promotion.

The assumption is made when using exposure scores $0,1,2$, and 3 that risk of lung cancer is not related to the duration of background level exposure. Periods when individuals had left the smelter and returned later did not contribute to any of the exposure measures in contrast to the SMR analysis, where they are included in duration of employment.

\section{Results}

PERSON-YEARS AT RISK

Table 2 shows SMRs by years of employment. The 
Table 2 SMRs for lung cancer by years of employment

\begin{tabular}{lcccr}
\hline $\begin{array}{l}\text { Years } \\
\text { employed }\end{array}$ & Observed & Expected & SMR & $95 \%$ CI \\
\hline $1-4$ & 43 & $49 \cdot 9$ & $86 \cdot 3$ & $62-116$ \\
$5-9$ & 23 & $21 \cdot 4$ & $107 \cdot 3$ & $68-161$ \\
$10-19$ & 36 & $29 \cdot 4$ & $122 \cdot 4$ & $86-170$ \\
$20-29$ & 44 & $23 \cdot 1$ & $190 \cdot 4^{* *}$ & $138-256$ \\
$30-39$ & 28 & $19 \cdot 7$ & $142 \cdot 1$ & $94-205$ \\
$\geqslant 40$ & 8 & $2 \cdot 74$ & $292 \cdot 2^{*}$ & $126-575$ \\
Total & 182 & $146 \cdot 2$ & $124 \cdot 5^{* *}$ & $107-144$ \\
\hline$* 0 \cdot 02 * * * * 0 \cdot 005$. & Probabilities under null hypothesis: SMR
\end{tabular}

${ }^{*}$ p 0.02; ${ }^{* *}$ p 0.005. Probabilities under null hypothesis: SMR $=100$.

overall SMR is significantly higher than 100 (p < 0.005 , two sided) as are SMRs for 40 or more years and 20-29 years.

There is an increasing trend in SMR with increasing duration of employment. A test of linear trend, using as the regressor variable the median duration of employment in each duration of employment group gives a $\chi_{1}^{2}$ of $12.6(p<0.001)$. Non-linear components are not statistically significant $\left(\chi_{4}^{2}=5 \cdot 3, p>0 \cdot 25\right)$.

The regression of SMR against duration of employment shows that SMR increases by a factor of 1.25 (95\% CI: $1 \cdot 11-1 \cdot 40)$ for every 10 years of employment at the plant from an initial SMR of 88 (95\% CI: 69-113).

Tests of homogeneity for lung cancer SMRs were age at risk: $\chi_{7}^{2}=6.58, \mathrm{p}>0.4$; date of hire: $\chi_{3}^{2}=7.62$, $\mathrm{p}<0.1$; calendar period of risk: $\chi_{7}^{2}=5.71, \mathrm{p}>0.5$; and level of exposure to cadmium: $\chi_{1}^{2}=0.37, p>0.5$. Thus there is little evidence of an association between lung cancer and these factors.

\section{MATCHED LOGISTIC REGRESSION}

Table 3 shows the relative risks associated with different durations of employment relative to subjects employed for under five years. The pattern of increasing risk with increasing duration of service confirms the SMR results in table 2, with the 20-29 years and the $\mathbf{4 0}$ or more years having significantly high risk. In table 4 duration of employment is taken as a continuous variable in three separate models. The "overall" relative risk of lung cancer increases by a factor of 1.33 (95\% CI: $1 \cdot 10-1 \cdot 61)$ for every 10 years employed. This is consistent with the SMR results and is significantly greater than $1\left(\chi_{1}^{2}=8.51, \mathrm{p}<0.005\right)$.

Table 4 also shows the relative risk attaching to every 10 years employment in each department. As the results are taken from a single regression model the risk associated with each department takes account of employment in other departments. With the possible exception of the cadmium plant and horizontal distillation, all departments show a raised relative risk around the overall level of 1.33 per 10 years reported above. A model discriminating only between occupa-
Table 3 Relative risks associated with duration of employment

\begin{tabular}{llll}
\hline $\begin{array}{l}\text { Years } \\
\text { employed }\end{array}$ & $\begin{array}{l}\text { No of } \\
\text { cases }\end{array}$ & $\begin{array}{l}\text { Relative } \\
\text { risk }\end{array}$ & $95 \%$ CI \\
\hline $1-4$ & 41 & 1 & (Reference group) \\
$5-9$ & 19 & 0.96 & $0.54-1 \cdot 71$ \\
$10-19$ & 34 & 0.94 & $0.56-1.58$ \\
$20-29$ & 45 & 2.08 & $1.25-3.44$ \\
$30-39$ & 27 & 1.82 & $0.85-3.92$ \\
$\geqslant 40$ & 8 & 6.89 & $1.74-27.3$ \\
\hline
\end{tabular}

*Apparent inconsistencies with table 2 because periods of absence from plant not included in years employed.

tions with background and those with above background exposures produces relative risk estimates of 1.28 and 1.34 per 10 years respectively, suggesting roughly similar levels of risk throughout the plant.

To examine the relation between levels of exposure to the various contaminants and risk, without making assumptions about how the dose response curves relate to the "low," "medium," and "high" levels, table 5 shows the relative risk associated with 10 years at each level of exposure. Six models were fitted, one for each of cadmium, zinc, sulphur dioxide, arsenic, lead, and dust. The results for each contaminant are therefore not adjusted for exposure to others.

For cadmium, table 5 shows that with increasing levels of exposure independent of duration, the relative risk follows the overall relative risk of 1.33 except for the $10-30 \mu \mathrm{g} / \mathrm{m}^{3}$ which gives a relative risk of $2 \cdot 11$. This, however, is based on only four cases. With regard to the other contaminants, there is a suggestion of an increasing risk of lung cancer for lead with increasing levels of exposure. This pattern may also be seen for arsenic, although the relative risk of

Table 4 Relative risks associated with 10 years employment in each department: three models $(a, b$, and $c)$

\begin{tabular}{|c|c|c|c|}
\hline Department & $\begin{array}{l}\text { No of cases } \\
\text { working at } \\
\text { least } \\
\text { one year }\end{array}$ & $\begin{array}{l}\text { Relative } \\
\text { risk }\end{array}$ & $95 \% C I$ \\
\hline $\begin{array}{l}\text { Cadmium plant } \\
\text { Sinter } \\
\text { Horizontal distillation } \\
\text { Acid } \\
\text { Furnace } \\
\text { Maintenance staff } \\
\text { Vertical retort } \\
\text { Other above background } \\
\text { Background } \\
\text { Unclassified }\end{array}$ & $\begin{array}{l}\text { Model a } \\
3 \\
18 \\
21 \\
12 \\
13 \\
66 \\
22 \\
22 \\
41 \\
16\end{array}$ & $\begin{array}{l}0 \cdot 72 \\
1 \cdot 39 \\
1 \cdot 03 \\
1 \cdot 34 \\
1 \cdot 47 \\
1 \cdot 36 \\
1 \cdot 33 \\
1 \cdot 24 \\
1 \cdot 26 \\
1 \cdot 37\end{array}$ & $\begin{array}{l}0.17-3.06 \\
1.02-1.89 \\
0.66-1.61 \\
0.99-1.81 \\
0.89-2.45 \\
1.09-1.69 \\
0.99-1.79 \\
0.86-1.78 \\
0.96-1.67 \\
0.88-2.14\end{array}$ \\
\hline $\begin{array}{l}\text { Background } \\
\text { Above background }\end{array}$ & $\begin{array}{l}\text { Model b } \\
41 \\
146\end{array}$ & $\begin{array}{l}1 \cdot 28 \\
1 \cdot 34\end{array}$ & $\begin{array}{l}0.97-1.69 \\
1 \cdot 10-1.62\end{array}$ \\
\hline Overall & $\underset{174}{M o d e l c}$ & $1 \cdot 33$ & $1 \cdot 10-1 \cdot 61$ \\
\hline
\end{tabular}


Table 5 Estimated relative risks associated with 10 years employment at each exposure level

\begin{tabular}{|c|c|c|c|c|}
\hline & $\begin{array}{l}\text { Exposure } \\
\text { level }\end{array}$ & $\begin{array}{l}\text { No of cases } \\
\text { working } \\
\text { at least } \\
\text { one year }\end{array}$ & $\begin{array}{l}\text { Relative } \\
\text { risk }\end{array}$ & $\begin{array}{l}\text { Standardised } \\
\text { normal } \\
\text { deviate }\end{array}$ \\
\hline \multirow{4}{*}{$\begin{array}{l}\text { Cadmium } \\
\left(\mu \mathrm{g} / \mathrm{m}^{3}\right)\end{array}$} & 1 & 88 & $1 \cdot 30$ & $2 \cdot 31$ \\
\hline & $2-5$ & 114 & $1 \cdot 34$ & $2 \cdot 78$ \\
\hline & $10-30$ & 4 & $2 \cdot 11$ & $1 \cdot 07$ \\
\hline & $40-60$ & 21 & $1 \cdot 34$ & $1 \cdot 84$ \\
\hline \multirow[t]{4}{*}{ Zinc } & 0 & 76 & $1 \cdot 28$ & $2 \cdot 13$ \\
\hline & 1 & 89 & $1 \cdot 36$ & 2.95 \\
\hline & 2 & 27 & $1 \cdot 35$ & 2.00 \\
\hline & 3 & 23 & $1 \cdot 17$ & 0.76 \\
\hline \multirow[t]{3}{*}{$\mathrm{SO}_{2}$} & 0 & 105 & $1 \cdot 28$ & $2 \cdot 27$ \\
\hline & 1 & 73 & $1 \cdot 36$ & $2 \cdot 82$ \\
\hline & 2,3 & 29 & $1 \cdot 39$ & $2 \cdot 55$ \\
\hline \multirow[t]{3}{*}{ Arsenic } & 0 & 66 & $1 \cdot 25$ & 1.81 \\
\hline & 1 & 134 & $1 \cdot 36$ & $3 \cdot 01$ \\
\hline & 2 & 2 & 2.05 & 0.98 \\
\hline \multirow[t]{4}{*}{ Lead } & 0 & 57 & $1 \cdot 25$ & 1.69 \\
\hline & 1 & 73 & $1 \cdot 28$ & $2 \cdot 06$ \\
\hline & 2 & 72 & $1 \cdot 36$ & $2 \cdot 81$ \\
\hline & 3 & 27 & $1 \cdot 54$ & $2 \cdot 08$ \\
\hline \multirow[t]{3}{*}{ Dust } & 0 & 102 & $1 \cdot 30$ & 2.42 \\
\hline & 1 & 40 & $1 \cdot 33$ & 1.94 \\
\hline & 2,3 & 73 & $1 \cdot 37$ & $2 \cdot 86$ \\
\hline
\end{tabular}

2.05 in the highest exposure category is again based on few cases. Otherwise the results are again consistent with the overall relative risk of 1.33 per 10 years employment anywhere in the plant.

The relative risks associated with cumulative exposures in table 6 have each been estimated independently of the others, representing six separate models. The units are in $\mathrm{mg} / \mathrm{m}^{3}$ years for cumulative cadmium and in "level-decades" for the other substances. For example, an estimated risk of 2.0 would indicate a doubled risk for 10 years at exposure level 1 , or for five years at level 2 , or 3.3 years at level 3 . The implied assumption about the quantitative relation between risks attaching to different exposure levels is generally supported by table 5 , although the data would be consistent with other assumptions that conformed to the same ranking of levels. Only the relative risks associated with arsenic and lead are statistically significant $(\mathrm{p}<0.025$, and $\mathrm{p}<0.01$ ).

The likelihood ratio $\chi^{2}$ of a model with terms for both arsenic and lead is 7.26 on 2 degrees of freedom and a model with all six exposures gives 7.59 on 6 degrees of freedom. Compared with the $\chi^{2}$ of 6.31 and 6.84 for arsenic and lead individually, these results mean, firstly, that once arsenic and lead are accounted for, the contribution of the other four substances to the risk of lung cancer is negligible $\left(\chi_{4}^{2}=0.33, p>\right.$ $0 \cdot 5)$. Secondly, once either lead or arsenic is accounted for, the other has no statistically significant association with lung cancer (lead: $\chi_{1}^{2}=0.95, \mathrm{p}>0.25$, arsenic: $\chi_{1}^{2}=0.42, \mathrm{p}>0.5$ ).

This effect is due to the high correlation between cumulative exposure to arsenic and lead. Cumulative
Table 6 Relative risks associated with each cumulative exposure and $\chi^{2}$ likelihood ratio statistic: six separate models

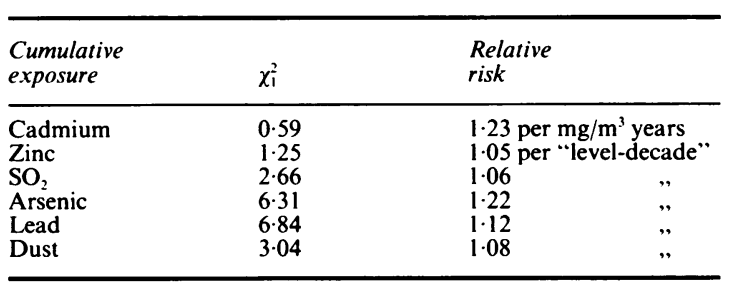

exposure measures are necessarily correlated, even if the year by year exposures are not, simply because they all correlate with duration of employment. A more relevant indication of association between cumulative exposures is the partial correlation (table 7), which removes the effect of any joint correlation with duration of employment. Several partial correlations are over 0.5: those between cadmium and sulphur dioxide, between arsenic and zinc, and between dust and lead. The partial correlation between arsenic and lead is particularly high at 0.72 .

Once cumulative arsenic and lead are accounted for, the contribution of total years of employment is not statistically significant $\left(\chi_{1}^{2}=2 \cdot 4, p>0 \cdot 1\right)$. This suggests that the association between years of employment and risk of lung cancer may be accounted for by cumulative arsenic or lead, or both. Alternatively, the effect on mortality of exposure to arsenic and lead after accounting for years of employment is also not statistically significant $\left(\chi_{2}^{2}=1 \cdot 2, \mathrm{p}>0.5\right)$. Interactions between pairs of exposures were tested. There was no evidence for synergistic effects.

The estimated relative risk attaching to 10 years work in the beryllium-copper plant was 0.93 (95\% CI: $0 \cdot 04-20 \cdot 5$ ). Only one of the 174 cases and 13 of the 2717 controls ever worked there.

\section{Discussion}

The interpretation of the overall lung cancer SMR of 125 is complicated by uncertainty over appropriate background rates. Social class, smoking, and regional factors need to be considered. Our use of the South

Table 7 Correlations of cumulative exposures with duration of employment and partial correlations between them controlling for duration of employment

\begin{tabular}{llrrrrr}
\hline & $\begin{array}{l}\text { Years } \\
\text { employed }\end{array}$ & Cadmium & Zinc & \multicolumn{1}{c}{$\mathrm{SO}_{2}$} & Arsenic & Lead \\
\hline Cadmium & 0.42 & & & & & \\
Zinc & 0.59 & 0.07 & & & & \\
$\mathrm{SO}_{2}$ & 0.52 & 0.56 & -0.24 & & & \\
Arsenic & 0.75 & 0.24 & 0.59 & 0.44 & & \\
Lead & 0.71 & 0.20 & 0.35 & 0.32 & 0.72 & \multirow{2}{*}{0.55} \\
Dust & 0.45 & -0.23 & -0.04 & -0.04 & 0.23 & 0.53 \\
\hline
\end{tabular}


West Urban Aggregates' (SMR 87) as a background could be criticised on the grounds that about $85 \%$ of the cohort lives in Bristol (SMR 103) and the remaining $15 \%$ in the rural surroundings (SMR 74 for SW Rural Aggregates). Modelling the SMR data in table 2 provides some evidence relevant to this issue as the fitted intercept may be interpreted as an SMR at zero years employment. Use of the SW Urban Aggregates as background gives a fitted intercept of 88 , suggesting that if anything this correction factor is already conservatively high. Use of a weighted Bristol rural background (98.7) would further reduce the intercept to 78 (95\% CI: $61-99)$, so low as to indicate that it would be an overcorrection. The same argument weighs against any downward adjustment of the observed SMRs to allow for factors such as the higher lung cancer mortality among manual workers and their smoking habits.

The low fitted intercept and the low SMR attaching to shorter durations of employment - for example, 86 for one to four years employment-suggest the possibility of a "healthy worker effect."16 The SMR for one to four years employment, however, does not increase with duration of follow up, suggesting that the increase in SMR with duration of employment is not due to an initial selection for good health that wears off with time. Moreover, the MLR analysis would eliminate any effects of this sort, as it compares the durations of employment of cases and controls at exactly the same duration of follow up, but none the less, it shows a similar result. As the MLR matches for date of hire and for birthdate, it also controls for the possible effect of the increasing relative disadvantage of manual workers over time ${ }^{17}$ and for the exposure of those who have been employed for longer periods to what may have been more hazardous conditions in the past.

Finally, workers with longer periods of employment at the smelter could be those who smoked more. We have no smoking data for the whole cohort but the proportion smoking among the 274 workers in the biological monitoring exercise varied between $90 \%$ and $85 \%$ with increasing duration of employment. ${ }^{18}$

While the appropriateness of the background mortality rate, and the unrepresentative distribution of social class and of smoking, would be relevant to the interpretation of an overall excess risk, these factors cannot easily explain the finding of an increasing risk of lung cancer with increasing years of employment. It is likely to be related to the smelter, to the extent that a correlation between duration of employment and exposure to carcinogens unconnected with the smelter is improbable, although such an association cannot be excluded.

\section{CADMIUM}

This study provides no evidence that cadmium, in the concentrations encountered in the smelter, is a cause of lung cancer, although there was an excess risk of lung cancer overall. Apart from the lack of association between mortality and cumulative cadmium (table 6) and the lack of relationship with years at given levels of cadmium (table 5), only 21 cases ever worked in departments with substantial exposures to cadmium (sinter and cadmium plant). Therefore, even if the relative risk in these departments was as high as 2 less than one third of the observed excess ( 36 cases) would be attributable to exposure in these two departments.

Exposures to cadmium were considerably lower than those in other cadmium studies where excesses of lung cancer have been found. Thun et al report exposures up to $100-1500 \mu \mathrm{g} / \mathrm{m}^{3}$ in high exposure areas before 1960 and seven out of 16 cases had cumulative exposures exceeding $200 \mu \mathrm{g} / \mathrm{m}^{3}$ for 40 years or over $8 \mathrm{mg} / \mathrm{m}^{3}$ years. ${ }^{6}$ This group had a risk of 5.3 relative to the lowest exposure group. In the present study, by contrast, the maximum average exposures have been assumed to be $60 \mu \mathrm{g} / \mathrm{m}^{3}$, and only $10 \%$ of cumulative exposures were above $0.5 \mathrm{mg} / \mathrm{m}^{3}$ years. On the other hand, average duration of exposure was over 14 years, far in excess of the three years reported in the study of Thun et al. The importance of duration of exposure with regard to the induction of cancer is not known.

Sorahan and Waterhouse report exposures of from 600 to $2800 \mu \mathrm{g} / \mathrm{m}^{3}$ in a nickel-cadmium battery plant in 1949 , falling in stages to below $200 \mu \mathrm{g} / \mathrm{m}^{3}$ by $1967 .{ }^{19}$ Lung cancer mortality was significantly related to duration of employment in "high or moderate exposure" jobs, though not in high exposure jobs alone. They add that exposure to cadmium entailed high exposure to nickel and that oxy-acetylene welding fume was also a potentially confounding exposure.

\section{ARSENIC}

In the study of Thun et al arsenic was present as a contaminant in the ore and was a potentially confounding factor. ${ }^{6}$ Excess lung cancer associated with arsenic has been reported in most studies of copperarsenic smelters ${ }^{20-25}$ and positive dose response relation have been established. ${ }^{21-24}$ Average exposures have been of the order of $500 \mu \mathrm{g} / \mathrm{m}^{3},{ }^{24}$ and $3-300 \mu \mathrm{g} / \mathrm{m}^{3}$ in the study of Pinto et al $^{23}$ with an estimated average of $50 \mu \mathrm{g} / \mathrm{m}^{3}$, according to WHO ${ }^{26}$ who also state that 25 working years at this level would nearly treble mortality from lung cancer above age 65 .

Exposure to arsenic in the cadmium smelter study by Thun et al appears to have been at a level comparable with the above studies ${ }^{6}: 300-700 \mu \mathrm{g} / \mathrm{m}^{3}$ in the worst areas, an average of $125 \mu \mathrm{g} / \mathrm{m}^{3}$ when use of respirators is accounted for. On the basis of assessments by the US Occupational Safety and Health Administration, Thun et al argue that this could not have produced the observed excess of lung cancer. 
Nevertheless, the areas of exposure to arsenic, accounting for $20 \%$ of all person years of exposure, were in the roasting and calcine furnace departments, which are also the areas of highest exposure to cadmium. Given the wide confidence interval in the group with the highest exposure to cadmium (SMR $280,95 \%$ CI 113-577), and the uncertainty surrounding exposure to arsenic, it is not clear whether cadmium or arsenic, or both, were responsible for the reported excess in the study of Thun et al.

In the present study cumulative exposure to arsenic was among the factors associated with lung cancer, but the only available airborne arsenic measurements range from 1 to $7 \mu \mathrm{g} / \mathrm{m}^{3}$, which would seem far too low to account for the excess lung cancer when judged by the standard of the copper-arsenic smelter studies. ${ }^{20-25}$ These measurements were taken between 1981 and 1983 but we have no information about previous levels.

\section{LEAD}

The International Agency for Research on Cancer concluded in 1980 and reconfirmed in 1982 that the data then available were inadequate to evaluate the carcinogenicity of lead compounds. ${ }^{27} 28$ In a British study of lead battery workers where the mean blood lead concentration was not dissimilar to concentrations in the present study an excess of malignant neoplasms of the digestive tract was found in men in the group with high exposure to lead dying in service ( 21 observed, 12.56 expected; $p=0.009$ ). This excess was considered unlikely to be related to exposure to lead. ${ }^{29}$ In a study of smelter workers where, as in our study zinc, arsenic, lead, sulphur dioxide, and dust were all major contaminants, cancer of the respiratory tract showed an SMR of $111(95 \% \mathrm{CI}: 80-151){ }^{30}$ Cooper $e t$ al found excess lung and stomach cancer in lead battery workers (SMR 124, 95\% CI: 102-150; SMR 168, 95\% CI: 116-235) and a similar, but not significant, excess in lead smelter workers (SMR 125, 95\% CI: 89-169; SMR 146, 95\% CI: 67-278). ${ }^{31}$ Confounding factors, in particular ethnic origin and cigarette smoking, could not be excluded and the exposure data were inadequate to seek evidence of a dose response relationship.

In a study of Swedish smelter workers an excess mortality was observed for lung cancer (SMR 218, 95\% CI: 173-264) and for stomach cancer (SMR 143, 95\% CI: 102-185) ${ }^{32}$ In those workers employed for at least three years at worksites with verified high exposure to lead lung cancer mortality remained raised (SMR 160, 95\% CI: 69-315). When these workers were subdivided by cumulative exposure to lead there was no evidence of a higher mortality in the group with high exposure to lead compared with the low, though with only eight deaths from lung cancer among the workers exposed to lead, the study had low power to detect any difference.

In our cohort exposures to lead were likely to have been increasing since the early 1950s and were high between 1968 and 1972, when over $50 \%$ of lead in air readings occasionally exceeded $2000 \mu \mathrm{g} / \mathrm{m}^{3}$ and 40 cases of lead poisoning were notified. ${ }^{8}$ Since then, exposures to lead have been substantially decreased, although a few workers each year had blood concentrations above $70 \mu \mathrm{g} / 100 \mathrm{ml}$. While a statistically significant association was found in the present study between cumulative exposure to lead and lung cancer mortality, this association cannot be considered causal.

\section{OTHER CONTAMINANTS}

Lung cancer has been associated with a wide range of metal smelting and refining processes apart from those already cited, ${ }^{33-38}$ and with coal carbonisation..$^{39}$ We are not aware, however, of other contaminants at the smelter present in concentrations sufficient to explain the present results on their own.

Asbestos insulation was used in the smelter and from the two cases of mesothelioma in the cohort it may be computed from studies of workers exposed to asbestos insulation ${ }^{40}$ that about six cases of lung cancer of the 36 excess may be attributed to asbestos.

In conclusion, the analysis shows that lung cancer mortality is positively related to duration of employment and to cumulative exposure to arsenic and lead but not to cumulative exposure to cadmium. The duration of employment effect could have arisen due to a real association between lung cancer mortality and cumulative arsenic or lead, or both, together with a correlation between the latter and duration of employment. Some support for this is provided by table 5, which suggests that increasing levels of exposure to arsenic and to lead for a given period are associated with a higher risk. Nevertheless, the association with cumulative arsenic and lead which are themselves highly correlated could have occurred because both correlate closely with duration of employment and thus with exposure to the several known or suspected carcinogens present at the site.

A combination of these and other substances, such as sulphur dioxide, acting independently or synergistically could have given rise to an association between duration of employment and lung cancer without generating a clear dose response effect for any particular contaminant. Whereas interpretations of this sort do not lead to the identification of specific carcinogens, and do not immediately suggest any simple control measures, they may provide a more realistic picture than studies where one contaminant is considered without taking proper account of the others. Investigations are being undertaken in the 
smelter in an attempt to identify the causes of the excess of lung cancer.

This research was supported by a grant from the International Lead Zinc Research Organisation to Professor Kazantzis.

We thank all those who have helped in preparing this paper, in particular: Professor Charles E Rossiter and $\mathrm{Mr}$ Keith Sullivan, Department of Occupational Health, London School of Hygiene and Tropical Medicine, and Dr B G Armstrong, School of Occupational Health, McGill University.

\section{References}

1 Armstrong BG, Kazantzis G. The mortality of cadmium workers. Lancet 1983;i:1424-7.

2 Kipling MD, Waterhouse AH. Cadmium and prostatic carcinoma. Lancet 1967;i:730-1.

3 Lemen RA, Lee JS, Wagoner JK, Blejer HP. Cancer mortality among cadmium production workers. Ann NY Acad Sci 1976;271:273-9.

4 Armstrong BG, Kazantzis G. Prostatic cancer and chronic respiratory and renal disease in British cadmium workers: a case-control study. Br J Ind Med 1985;42:540-5.

5 Takenaka S, Oldiges M, Konig H, Hochrainer D, Oberdorster G. Carcinogenicity of cadmium aerosols in Wistar rats. $J$ Natl Cancer Inst 1983;70:367-73.

6 Thun MJ, Schnorr TM, Smith AB, Halperin WE, Lemen RA. Mortality among a cohort of US cadmium production workers-an update. J Natl Cancer Inst 1985;74:325-33.

7 Kazantzis G, Armstrong BG. Renal function in relation to low levels of cadmium exposure in a group of smelter workers. Environ Health Perspect 1984;54:193-9.

8 Report of a Committee appointed to inquire into lead poisonings at [a smelter]. London: HMSO, 1972. (Windeyer report.)

9 Berry G. The analysis of mortality by the subject-years method. Biometrics 1983;39:173-84.

10 Baker RJ, Nelder JA. The GLIM system release 3, generalised linear interactive modelling. Oxford: Numerical Algorithms Group, 1983.

11 Breslow NE, Day NE. Statistical methods in cancer research. Vol 1. The analysis of case control studies. Lyon: International Agency for Research on Cancer, 1980. (IARC sci publ No 32.)

12 Breslow NE, Lubin JH, Marek P, Langholz B. Multiplicative models and cohort analysis. Journal of the American Statistical Association 1983;78:1-12.

13 Storer BE, Wacholder S, Breslow NE. Maximum likelihood fitting of general risk models to stratified data. Applied Statistics 1983;32:172-81.

14 Doll R. Occupational cancer: problems in interpreting human evidence. Ann Occup Hyg 1984;28:291-305.

15 Doll R, Peto R. Mortality in relation to smoking: 20 years observations on male British doctors. Br Med J 1976;ii:1525-36.

16 Fox AJ, Collier PF. Low mortality rates in industrial cohort studies due to selection for work and survival in the industry. $\mathrm{Br}$ J Prev Soc Med 1976;30:225-30.

17 Marmot MG, McDowall ME. Mortality decline and widening social inequalities. Lancet 86;ii:274-6.
18 Ades AE, Kazantzis G. Lung cancer and chronic respiratory disease mortality in a non-ferrous smelter. (A report to ILZRO.) Research Triangle Park, USA: International Lead Zinc Research Organization, 1985.

19 Sorahan T, Waterhouse JAH. Mortality study of nickel cadmium battery workers by the method of regression models in life tables. Br J Ind Med 1983;40:293-300.

20 Lee AM, Fraumeni JF. Arsenic and respiratory cancer in man: an occupational study. J Natl Cancer Inst 1969;42:1045-52.

21 Lubin JH, Pottern LM, Blot WJ, Tokudome S, Stone BJ, Fraumeni JF. Respiratory cancer among copper smelter workers: recent mortality statistics. J Occup Med 1981;23:779-84.

22 Tokudome S, Kuratsune M. A cohort study on mortality from cancer and other causes among workers at a metal refinery. Intl $J$ Cancer 1976;17:310-7.

23 Pinto SS, Enterline PE, Henderson V, Varner MO. Mortality experience in relation to a measured arsenic trioxide exposure. Environ Health Perspect 1977;19:127-30.

24 Axelson O, Dahlgren E, Jansson CD, Rehnlund SO. Arsenic exposure and mortality: a case referent study from a Swedish copper smelter. Br J Ind Med 1978;35:8-15.

25 Enterline PE, Marsh GM. Cancer among workers exposed to arsenic and other substances in a copper smelter. Am J Epidemiol 1982;116:895-911.

26 World Health Organisation. Environmental health criteria 18: arsenic. Geneva: WHO, 1981.

27 International Agency for Research on Cancer. Monographs on the evaluation of carcinogenic risk of chemicals to humans. Vol 23. Some metals and metallic compounds. Lyon: IARC, 1980.

28 International Agency for Research on Cancer. Monographs on the evaluation of carcinogenic risk of chemicals to humans. Supplement 4. Lyon: IARC, 1982.

29 Malcolm D, Barnett HAR. A mortality study of lead workers. $\mathrm{Br} \mathrm{J}$ Ind Med 1982;39:404-10.

30 Selevan SG, Landrigan PJ, Stern FB, Jones JH. Mortality of smelter workers. Am J Epidiomol 1985;122:673-83.

31 Cooper WC, Wong O, Kheifetz L. Mortality in employees of lead battery plants and lead production plants, 1947-1980. Scand J Work Environ Health 1985;11:331-45.

32 Gerhardsson L, Lundström N-G, Nordberg G, Wall S. Mortality and lead exposure: a retrospective cohort study of Swedish smelter workers. Br J Ind Med 1986;43:707-12.

33 Pedersen E, Andersen A, Hogetveit A. Second study of the incidence and mortality of cancer of respiratory organs among workers at a nickel refinery. Ann Clin Lab Sci 1978;8:503-4.

34 Lessard R, Read D, Maheux B, Lambert J. Lung cancer in New Caledonia, a nickel smelting island. J Occup Med 1978;20: 815-7.

35 Blot WJ, Brown LM, Pottern LM, Stone BJ, Fraumeni JF. Lung cancer among long-term steel workers. Am J Epidemiol 1983;117:706-16.

36 Blot WJ, Fraumeni JF. Arsenical air pollution and lung cancer. Lancet 1975; ii: 142-6.

37 Brown LM, Pottern LM, Blot WJ. Lung cancer in relation to environmental pollutants emitted from industrial sources. Environ Res 1984;34:250-61.

38 Rencher AC, Carter MW, McKee DW. A retrospective epidemiological study of mortality in a large Western copper smelter. J Occup Med 1977;19:754-8.

39 Doll R, Vessey MP, Beasley RWR, et al. Mortality of gasworkers-final report of a prospective study. Br J Ind Med 1972;29:394-406.

40 Doll R, Peto J. Asbestos: effects on health of exposure to asbestos. (Health and Safety Executive.) London: HMSO, 1985. 